\title{
Identification of a region in the human IRS2 promoter essential for stress induced transcription depending on SP1, NFI binding and ERK activation in HepG2 cells
}

\author{
M Udelhoven, U Leeser, S Freude, M M Hettich, M Laudes, J Schnitker, W Krone \\ and $\mathbf{M}$ Schubert
}

Department of Internal Medicine II, Center for Molecular Medicine Cologne (CMMC), and Cologne Excellence Cluster on Cellular Stress Responses in Aging-Associated Diseases (CECAD), University of Cologne, Kerpener Strasse 62, 50937 Cologne, Germany

(Correspondence should be addressed to M Schubert; Email: markus.schubert@ uni-koeln.de)

\begin{abstract}
Recent studies have discovered changes in the insulin-/IGF1 signaling affecting glucose metabolism and the molecular pathogenesis of human hepatocellular cancer. Insulin/IGF1 receptor mediates its intracellular effects by recruitment of one out of the four different insulin receptor substrates (IRS). To investigate mechanisms of IRS2 expression, we analyzed transcriptional regulation of IRS2 in human HepG2 cells. We identified a region 688 bp upstream of the translation start codon responsible for $\sim 90 \%$ of basal human IRS2 promoter activity in HepG2 cells, and confirmed binding of specificity protein 1 (also called Sp1 transcription factor, SP1) and nuclear factor 1 (NFI) in this region. Mutation of both SP1 and NFI binding sites or inhibition of extracellular signal regulated kinase (ERK) suppressed IRS2 promoter activity almost completely, revealing a major role of MAP kinases (MAPK) for IRS2 transcription. Activating this cascade with oxidative stress increased IRS2 promoter activity and endogenous IRS2 expression substantially. IRS2 promoter activity rose even more after additional inhibition of p38MAPK indicating an inhibitory effect of p38MAPK on ERK mediated IRS2 transcription. Activation of the MAPK pathway using interleukin 1, beta (IL1B) increased IRS2 promoter activity similar to oxidative stress. In contrast IL1B decreases and inhibition of the MAPK pathway increases IRS1 promoter activity revealing opposed effects of IL1B and ERK on the expression of different IRS proteins. In conclusion we discovered a specific region $(-688$ to $-611 \mathrm{bp})$ in the IRS2 promoter essential for basal promoter activity and oxidative stress induced transcription depending on ERK activation and SP1 and NFI binding in human hepatocytes.
\end{abstract}

Journal of Molecular Endocrinology (2010) 44, 99-113

\section{Introduction}

Insulin receptor substrate (IRS) proteins integrate signals from the insulin/insulin-like growth factor 1 (IGF1) receptor (IGF1R) with those generated by proinflammatory cytokines and nutrients. The IRS2 branch of insulin/IGF1 signaling controls both hepatic insulin response as well as pancreatic $\beta$-cell growth and function. Moreover, IGF1Rs are frequently overexpressed in human hepatocellular cancer (HCC), and this overexpression has been correlated with increased tumor growth (Lee et al. 2007). Inhibition of the IGF1R tyrosine kinase induces growth inhibition, apoptosis, and cell cycle arrest in human HCC cell lines. These observations suggest an important role for insulin/ IGF1R signal transduction in HCC development or growth. IRS are adapter proteins that couple different receptor tyrosine kinases to downstream signaling proteins, building up complex signaling networks (Fisher \& White 2004). The function of IRS proteins has been analyzed using different Irs knockout mice (Biddinger \& Kahn 2006). However, these mice present with differing phenotypes: Irs 1 knockout animals are $50 \%$ smaller than their wild-type littermates without diabetic phenotype, whereas Irs 2 knockout mice show a nearly normal body growth and develop diabetes due to pancreatic $\beta$-cell failure and hepatic insulin resistance (Burks et al. 2000, Schubert et al. 2003). Thus, the IRS proteins might have unique functions in intracellular signaling, which has been referred to the phosphorylation of tyrosine and serine residues in different amino acid recognition motives. This enables the specific binding of downstream SH2 domain containing signaling molecules like phosphoinositide 3 (PI3)kinase (Shepherd et al. 1998) and Grb2 (Valverde et al. 2001) to the particular IRS protein. The signaling potential and the physiological effects of each IRS protein might not only be represented by different tyrosine phosphorylation dependent binding sites for downstream proteins, but also by the abundance of every single IRS protein in a specific tissue.

One of the most important aspects of protein expression is its transcriptional regulation in different tissues (Vassen et al. 1999). The mechanisms leading to

DOI: 10.1677/JME-08-0182 Online version via http://www.endocrinology-journals.org 
transcriptional activation of the IRS2 gene are still unclear. It has been shown that insulin is able to suppress the expression of IRS1 and -2 in Fao hepatoma cells (Hirashima et al. 2003). This effect could be diminished using a PI3-kinase inhibitor. Concerning the mechanism the authors described a PI3-kinase dependent binding of transcription factors to an insulin responsive element (IRE). Furthermore, insulin is able to partially downregulate reporter gene activity under IRS2 promoter regulation in rat hepatocytes (Zhang et al. 2001). The heptanucleotide TGTTTTG that functions as an IRE has been characterized in the enhancer region of the phosphoenolpyruvate carboxykinase gene (Hall et al. 2006). This sequence matches to a region found by Zhang in the IRS2 promoter (Zhang et al. 2001) and might be important for the regulation of genes involved in metabolic processes. Impaired expression of IRS2 as it is described under hyperinsulinemic conditions (Hirashima et al. 2003) could be an important component in the development of hepatic insulin resistance and type 2 diabetes.

The only model so far describing the function of one part of the IRS2 promoter in detail is based on the finding that sterol regulatory element binding proteins (SREBPs) are able to suppress IRS2 mediated insulin signaling in the liver (Ide et al. 2004, Shimano 2007). Using luciferase reporter analysis, Ide et al. (2004) found that the forkhead transcription factor FOXO3 induced IRS2 promoter activity, which could be downregulated by overexpression of SREBP-1a and -1c. Furthermore, PPAR $\gamma$ coactivator-1 enhanced FOXO3 induced activation of the IRS2 promoter. This effect could also be suppressed by SREBP-1. In the same promoter region TFE3 was found to be an important transcription factor that activates IRS2 promoter activity. TFE3 binds an E-box that overlaps in sequence with the SREBP-1 binding site and sits beside the FOXO3 binding site (Nakagawa et al. 2006), whereas TFE3 activates the promoter synergistically with FKH transcription factor O1 (FOXO1).

Until now all published studies on the human IRS2 promoter focus on metabolic feedback signals regulating the promoter activity. However, IRS2 mediates not only metabolic but also important growth and proliferation signals. IRS2 knockout mice show impaired neuronal proliferation but normal body growth (Schubert et al. 2003) indicating a tissue specific regulation of proliferation via IRS2. Overexpression of IRS1 or -2 induces tumorigenesis of the mammary gland (Dearth et al. 2006) and IRS2 expression promotes metastasis (Jackson et al. 2001, Nagle et al. 2004) underlining the importance of IRS2 expression for human diseases. Furthermore, $80 \%$ of human hepatocellular carcinomas overexpress IRS2, suggesting a major role for IRS2 in liver carcinogenesis and tumor growth (Boissan et al. 2005, Cantarini et al. 2006). During liver regeneration after partial hepatectomy IRS2 expression increases time-dependently (Escribano et al. 2003). Thus, IRS2 expression in liver plays a specific role in regulating hepatic glucose metabolism as well as proliferation of hepatocytes and possible liver carcinogenesis.

To analyze transcriptional activation of IRS2 in human HepG2 cells, we cloned the human IRS2 promoter (over $2 \cdot 3 \mathrm{~kb}$ ), and identified a region $(-688$ to $-611 \mathrm{bp}$ ) that is essential for $\sim 90 \%$ of the basal and stress induced transcription of IRS2. This region lies about $100 \mathrm{bp}$ upstream of the previously described locus of the IRS2 promoter (Zhang et al. 2001) and is responsible for the metabolic feedback to the promoter and mediates basal as well as MAP kinase (MAPK) induced transcription of IRS2 in human hepatocytes.

\section{Materials and methods}

\section{Chromatin immunoprecipitation assay}

HepG2 cells were seeded on $10 \mathrm{~cm}$ dishes. One plate was used per experiment. Cells were kept serum free for $30 \mathrm{~h}$ and were then fixed with $1 \%$ formaldehyde for $10 \mathrm{~min}$ at RT. After $5 \mathrm{~min}$ glycine was added to a final concentration of $125 \mathrm{mM}$ for $5 \mathrm{~min}$. Plates were washed twice with ice-cold PBS and cells were harvested in $2 \mathrm{ml}$ PBS and centrifuged at $1000 \mathrm{~g}$. The pellet was lysed in lysis buffer ( $5 \mathrm{mM}$ PIPES $\mathrm{pH} 8,85 \mathrm{mM} \mathrm{KCl}, 0 \cdot 5 \% \mathrm{NP} 40$, $1 \times$ complete protease inhibitor (Roche)), and plasma membranes were destroyed by shearing through a 26 gouge needle. After $10 \mathrm{~min}$ on ice nuclei and cell debris were pelleted at $1000 \mathrm{~g}$. Afterwards the pellet was resuspended in $750 \mu \mathrm{l}$ high salt lysis buffer $(1 \times \mathrm{PBS}$, $1 \%$ NP40, $0 \cdot 5 \%$ sodium deoxycholate, $0 \cdot 1 \%$ SDS, $1 \times$ complete protease inhibitor) to crack the nuclei. After mixing, lysate was left on ice for $10 \mathrm{~min}$. Released DNA was sonicated four times for $30 \mathrm{~s}$ at $50 \%$ power using a sonicator (Sonoplus-M73, Bandelin, Berlin, Germany) on ice. Remaining cell debris was pelleted at $12000 \mathrm{~g}$ and the supernatant was used for immunoprecipitation. Samples were split and $350 \mu$ l were incubated with specific antibody ( $3 \mu \mathrm{g}$ ) (anti-specificity protein 1 (antiSP1) (H-225) X, anti nuclear factor 1 (NFI) (N-20) X (both Santa Cruz Biotechnology, Santa Cruz, CA, USA), anti RNApol II \#39097 (Active Motif, Rixensart, Belgium)) and $350 \mu \mathrm{l}$ with a nonspecific control antibody (3 $\mu$ g) (normal mouse IgG \#2025, normal rabbit IgG \#2027 (both Santa Cruz Biotechnology)), $50 \mu \mathrm{l}$ were left for input control. After incubating with antibody for $4 \mathrm{~h}$ at $4{ }^{\circ} \mathrm{C}$ on a shaker, blocked protein $\mathrm{G}$ agarose was added and incubation was continued overnight. Prior to usage protein $\mathrm{G}$ agarose was blocked in $1 \%$ BSA with $50 \mu \mathrm{g}$ salmon sperm DNA (Sigma-Aldrich, St Louis, MO, USA) in high salt lysis buffer. The day after beads were washed twice with lysis 
buffer and four times with wash buffer $(100 \mathrm{mM}$ Tris $/ \mathrm{HCl}$ $\mathrm{pH} 8 \cdot 0,500 \mathrm{mM} \mathrm{LiCl}, 1 \% \mathrm{NP} 40,1 \%$ sodium deoxycholate). After that antibody coupled protein was released by incubation in $150 \mu \mathrm{l}$ elution buffer ( $1 \%$ SDS, $0 \cdot 1 \mathrm{M}$ $\mathrm{NaHCO}_{3}$ ) for $1 \mathrm{~h}$ at $25^{\circ} \mathrm{C}$ shaking at 200 r.p.m. Agarose was pelleted and $\mathrm{NaCl}$ was added to the supernatant to a final concentration of $250 \mathrm{mM}$. Previously taken input controls were treated similarly. About $1 \mu \mathrm{l}$ RNaseA was added to each sample and after an incubation time of $2 \mathrm{~h}$ at $55^{\circ} \mathrm{C}$ with shaking $1 \mu \mathrm{l}$ proteinase $\mathrm{K}$ was added and temperature was raised to $67^{\circ} \mathrm{C}$. Samples were decrosslinked for a minimum time of $7 \mathrm{~h}$ or overnight. After that, DNA was cleaned up with PCR cleanup kit (Qiagen, Hilden, Germany) using $40 \mu$ as elution volume.

\section{PCR in chromatin immunoprecipitation assay}

PCR for chromatin immunoprecipitation (ChIP) assay was performed using $5 \mu \mathrm{l}$ of eluted DNA per sample. PCR was done with a standard 30 cycle PCR program using $55^{\circ} \mathrm{C}$ as annealing and $72^{\circ} \mathrm{C}$ as elongation temperature. Elongation time was $45 \mathrm{~s}$ and Taq polymerase LC (Fermentas International Inc, Burlington, $\mathrm{ON}$, Canada) was used in $1.5 \mathrm{mM} \mathrm{MgCl}_{2}$ containing PCR reaction buffer. Primers for ChIP PCR were: $5^{\prime}$-ACAAGCCGCTGATTAATGAGG C-3' ${ }^{\prime} 5^{\prime}$-TGACTCGGCGTTACGCAGGCAC-3' ${ }^{\prime}$ for IRS2 promoter and $5^{\prime}$-TACTAGCGGTTTTAC GGGCG-3' ${ }^{\prime}, 5^{\prime}$-CGAACAGGAGGAGCAGAGAGCGA-3' for GAPDH promoter. PCR samples were separated on a $1.5 \%$ agarose gel in TAE buffer.

\section{Cloning of IRS2 promoter luciferase reporter constructs}

Full-length - 2338bp-IRS2 promoter was amplified from human genomic DNA using the following primers: 5'-CCCAAATTCAGGCTACTGATCAATAATCC-3' , 5'-CCCACCGCTGCAGGAGCAC C-3', 5'-GAAGG GGGTGCTCCTGCAGCGGTG- ${ }^{\prime}$, and $5^{\prime}$-AAAAAGCTTCGCGGGCGCTTCAGGCC GCG-3'

The resulting two PCR-subfragments were cloned into pDrive (Qiagen) and pCR2.1 (Invitrogen). To construct the full-length promoter the fragments were ligated XhoI/PstI and PstI/HindIII into pGL2 basic (Promega). IRS2-1585bp-pGL2 was cut Xhol/HindIII out of IRS2-1585bp-pCR2.1 and ligated XhoI/HindIII into pGL2. The other IRS2 promoter fragments: $-1962,-1253,-824,-688,-611,-500$, and $-398 \mathrm{bp}$ were constructed using (5'-AAACTCGAGGCGCAGGATCGGGAGCTTG CTG-3' ${ }^{\prime}$ 5'-AAC TCGAGCTCGATCTGGAGCGCGGTGCTCGC-3' 5' $^{\prime}$-AACTCGGACAAGCCGCTGATTAATGAGGC-3' ${ }^{\prime}$ 5'-AACTCGAGCCGCGAGCGCCGCGCCGATTGGCCGAGC-3' ${ }^{\prime}$, 5'-AACTCGAGCGGCCGCGCTGTGTGTGCCTGCGTAA- ${ }^{\prime}$, 5'-AACTCGAGAGCCCGGGTCGCCGTTGGCAGC-3',
5'-ACTCGAGAGCGCGACGCGGCGGCAGCAGC-3') as forward and ( $5^{\prime}$-AAAGCTTCGCGGGCGCTTCAGGCCGCG-3') as reverse primer. IRS2 promoter full-length clone was used as template and fragments were ligated XhoI/HindIII into pGL2. IRS1 and -4 promoter luciferase reporter vectors were constructed likewise with primers listed in Supplementary Table 1, see section on supplementary data given at the end of this article.

\section{Dual luciferase reporter assay}

HepG2 and $\mathrm{HuH} 7$ cells were transfected with $0.5 \mu \mathrm{g}$ promoter reporter construct and $10 \mathrm{ng}$ pRLCMV (Promega) using $3 \mu$ l Rotifect (Carl Roth, Karlsruhe, Germany) per well in 24 well plates. After seeding cells in RPMI with $10 \%$ FCS and penicillin/streptomycin, cells were transfected the day after. After starving cells in RPMI without FCS for $30 \mathrm{~h}$, dual luciferase reporter assay was done according to manufacturer's instructions (Promega) using a Mithras LB940 luminometer (Berthold Technologies, Bad Wildbad, Germany). In case of pCMX-PPAR $\gamma$ cells were cotransfected with the indicated amounts of plasmid and the total amount of transfected DNA was kept constant at $0.5 \mu \mathrm{g}$ through addition of pcDNA3.1 (Invitrogen). GT1-7 cells were transfected with $0.2 \mu \mathrm{g}$ promoter reporter construct using $2 \mu \mathrm{l}$ Effectene (Qiagen) per well in 24 well plates. Cells were cultured in DMEM $4500 \mathrm{mg} / 1$ glucose, plus sodium pyruvate (Invitrogen). MCF-7 cells were transfected with Rotifect as described for HepG2 cells. All measurements were done in triplicates $(n=6$ independent experiments).

\section{Transfection of siRNA expression constructs}

HepG2 cells were transfected with $0.5 \mu \mathrm{g}$ per well with pSuper (Oligoengine Seattle, WA, USA), pSuper extracellular signal regulated kinase-1 (ERK-1), and pSuper ERK-2 in 24 well plates the day before cells were transfected with luciferase promoter reporter constructs. Rotifect was used as described above. In case of western blot experiments, cells were seeded and transfected in six well plates. Cells were lysed in lysis buffer $48 \mathrm{~h}$ after transfection.

\section{Electromobility shift assay}

Nuclear extracts were made from HepG2 cells that were starved in RPMI without FCS for $30 \mathrm{~h}$. All procedures were done at $4{ }^{\circ} \mathrm{C}$. About $10^{7}$ cells were pelleted, the plasma membrane was lysed in lysis buffer $(50 \mathrm{mM} \mathrm{KCl}$, $0.5 \%$ NP40, $25 \mathrm{mM}$ Hepes $\mathrm{pH} 8,125 \mu \mathrm{M}$ dithiothreitol (DTT), $1 \times$ complete protease inhibitor) and the sample was centrifuged. The resulting pellet was 
washed in washing buffer $(50 \mathrm{mM} \mathrm{KCl}, 25 \mathrm{mM}$ Hepes $\mathrm{pH} 8,125 \mu \mathrm{M}$ DTT, $1 \times$ complete protease inhibitor) and centrifuged again. The final pellet was resuspended in extraction buffer $(500 \mathrm{mM} \mathrm{KCl}, 25 \mathrm{mM}$ Hepes $\mathrm{pH} 8$, $10 \%$ glycerol, $125 \mu \mathrm{M}$ DTT, $1 \times$ complete protease inhibitor) to destroy nuclear membranes and snap frozen. After a last centrifugation step the protein concentration of the final supernatant was determined by Bradford assay. About $8 \mu \mathrm{g}$ nuclear extract was used per sample. Oligonucleotides used in electromobility shift assay (EMSA) were annealed to yield double strands in $10 \mathrm{mM}$ Tris- $\mathrm{HCl} \mathrm{pH} 8,50 \mathrm{mM} \mathrm{NaCl}$ and the binding reaction was performed using the LightShift Chemiluminescent EMSA Kit (Pierce Biotechnology Inc, Rockford, IL, USA). Oligonucleotides used for NFI and SP1 binding were: NFIwt short: 5'-GGGGGGCGCGGCGCCAATGCGAGGC-3'， 5'-GCCTCGCATTGGCGCCGCGCCCCCC-3' ${ }^{\prime}$, NFIwtSP1wt long: 5'-GCCGTCCGTCGGGGGGCGCGGCGCCAATGCGAGGCAGCGGGGCGGGGCGGCCG-3' 5' $^{\prime}$-CGGCCGCCCCGCCCCGCTGCCTCGCATTGGCGCCGCGCCCCCCGACGGACGGC-3' ${ }^{\prime}$, NFImut short: $5^{\prime}$-GGGGGGCGCGGCTAAAATGCGAGGC-3' ${ }^{\prime}$, $5^{\prime}$-GCCTCGCATTTTAGCCGCGCCCCCC-3', NFImutSP1wt long: 5'-GCCGTCCGTCGGGGGGCGCGGCTAAAATGCGAGGCAGCGGGGCGGGGCGGCCG-3' ${ }^{\prime}$ 5'-CGGCCGCCCCGCCCCGCTGCCTCGCATTTTAGCCGCGCCCCCCGACGGACGGC3', SP1wt short: 5'-GAGGCAGCGGGGCGGGGCGGCC$3^{\prime}$, 5'-GGCCGCCCCGCCCCGCTGCCTC-3' ${ }^{\prime}$, SP1mut short: $5^{\prime}$-GAGGCAGCGGTTCGGGGCGGCC-3 ${ }^{\prime}, 5^{\prime}$-GGCCGCCCCGAA-CCGCTGCCTC-3' ${ }^{\prime}$, NFIwtSP1 mut long: $5^{\prime}$ GCCGTCCGTCGGGGGGCGCGGCGCCAATGCGAGGCAGCGGTTCGGGGCGGCCG-3' ${ }^{\prime}$ 5'-CGGCCGCCCCGAACCGCTGCCTCGCATTGGCGCCGCGCCCCCCGACGGACGGC-3'. For supershift anti-SP1 (H-225) X and anti NFI (N-20) X (Santa Cruz Biotechnology) were used.

\section{Site directed mutagenesis}

NFI and SP1 binding sites on - 824bp-IRS2 pGL2 were mutagenized individually and together in case of the double mutant. Mutagenesis was performed using primers 5'-GGGCGCGGCTAAAATGCGAGGCAGCG$3^{\prime}, 5^{\prime}$-CCCGACGGACGGCGCGCTCGGCCAATCG-3 ${ }^{\prime}$ in case of NFI and $5^{\prime}$-GTGCCTGCGTAACGCCGAGTCACAT-3' ${ }^{\prime}$ 5'-ACACAGCGCGGCCGCCCCGAACCGCTGCCTCGCATTGGCGCC-3' in case of SP1. The double mutant was made using IRS2-824bp-NFImutpGL2 as template. Site directed mutagenesis PCR was done with Hifi Taq Proofreading Polymerase (Fermentas) with an annealing temperature of $60{ }^{\circ} \mathrm{C}, 72^{\circ} \mathrm{C}$ elongation for $8 \mathrm{~min}$ and 32 amplification cycles. Unmethylated plasmid DNA was digested with DpnI and relegated fragments were transformed into Escherichia coli.

\section{RT-PCR IRS2}

HepG2 cells were seeded in six well plates in RPMI with $10 \%$ FCS and penicillin/streptomycin. After an overnight incubation cells were kept in medium without serum for $30 \mathrm{~h}$ containing $\mathrm{H}_{2} \mathrm{O}_{2}$, PD98,059 (Sigma), and SB202190 (Sigma) in the indicated concentrations. Total RNA was extracted using RNeasy Mini Kit (Qiagen). RT-PCR was performed using One-StepRT-PCR Kit (Qiagen) with $1 \mu \mathrm{g}$ RNA and oligonucleotides specific for hIRS2 coding sequence ( $5^{\prime}$-TGAGCCACTGTGGCCGCTCCTAC-3' ${ }^{\prime}$ 5'-AACCGCACCACATGCGCATGTAC-3 ${ }^{\prime}$ ) and hGAPDH (5'-TACTAGCGGTTTTACGGGCG-3' ${ }^{\prime}$, 5'-TCGAACAGGAGGAGCAGAGAGCGA-3 ${ }^{\prime}$ ) for normalization. Each experiment was repeated five times. To quantify the changes in optical density, we used the software AIDA (Version 4.00.027; Raytest, Straubenhardt, Germany).

\section{Western blot}

HepG2 cells were seeded in six well tissue culture plates. A day after cells were starved and stimulated with rising amounts of $\mathrm{H}_{2} \mathrm{O}_{2}$ and with or without $50 \mu \mathrm{M}$ PD98,059. (Promega). After $30 \mathrm{~h}$ cells were collected in $500 \mu \mathrm{l}$ PBS. After centrifugation, the pellet was lysed in lysis buffer $\left(0.5 \%\right.$ SDS, $50 \mathrm{mM}$ Hepes $\mathrm{pH} 8,1 \mathrm{mM} \mathrm{Na} \mathrm{VO}_{3}$, $20 \mathrm{mM} \beta$-glycerophosphate, $1 \times$ complete protease inhibitor). About $80 \mu \mathrm{g}$ of total protein cell lysate was loaded per lane. SDS-PAGE was performed and proteins were blotted on PVDF membrane (Bio-Rad, Hercules, CA, USA). Membrane was incubated with $\alpha$ Erk-1/2 antibody (p44/42 MAPK \#9102, Cell Signaling Technology, Danvers, MA, USA) for loading control and with aphospho ERK-1/2 antibody (phosphop44/42 MAPK Thr202/Tyr204 \#9101, Cell Signaling Technology) for detection of phosphorylation signal. For inhibitor control experiments membranes were additionally incubated with acJun (H-79) \#sc1694 (Santa Cruz Biotechnology), ap53 (FL-393) \#sc6243 (Santa Cruz Biotechnology), and aATF2 (20F1) \#9226 (Cell Signaling Technology) for loading control and aphospho Jun (ser 63) \#9261 (Cell Signaling Technology), aphospho p53 (ser 46) \#2521 (Cell Signaling Technology), and aphosphoATF2 (thr 71) \#5112 (Cell Signaling Technology) for detection of phosphorylation. Additionally $\alpha \mathrm{SP} 1$ (H-225) \#sc14027 and $\alpha \mathrm{NFI}$ (H-300) \#sc5567 (both Santa Cruz Biotechnology) were used for expression analysis.

\section{Results}

\section{IRS2 promoter activity in HepG2 cells}

We cloned the promoters of IRS1 (2420 bp), IRS2 (2338 bp), and IRS4 (2338 bp). After confirmation of promoter sequences, the different promoters were 
cloned in pGL2 (Fig. 1A, Supplementary Table 1) and transfected into HepG2 cells. Dual luciferase reporter assays were carried out using the three promoter constructs. Full-length promoters showed high basal luciferase activity compared with mock transfection proving that the cloned sequences were promoters (data not shown). Interestingly, basal IRS2 promoter activity was much higher compared to the IRS1 and -4 promoter (Fig. 1B). To identify new transcription factors binding and modulating promoter activity of IRS2, the $2338 \mathrm{bp}$ full-length IRS2 promoter was cloned in pGL2 and deletion constructs getting shorter from upstream in steps of $300 \mathrm{bp}$ each were amplified using PCR (Fig. 1A). The experiments showed a decrease in activity for fragments shorter than $-824 \mathrm{bp}$ (data not shown). Further subconstructs indicated that there was a large activity breakdown between -688 and $-611 \mathrm{bp}$ and total loss of activity if the fragment was shorter than $611 \mathrm{bp}$ (Fig. 1C). After isolation of the potential activator sequence on the $77 \mathrm{bp}$ long fragment $(-688$ to $-611 \mathrm{bp}$ ), we searched for potential transcription factor binding sites in this sequence using MatInspector (www.genomatix.de). We discovered a potential binding motive for SP1: AGCGGGGCGGGGCGG and NFI: GGGGGGCGCGGCGCCAATG.

\section{IRS2 promoter is a target of SP1 and NFI}

First, we tested SP1 and NFI binding using EMSA. Oligonucleotides were annealed as described in Materials and methods and incubated with HepG2 nuclear extracts. Using oligonucleotides containing the SP1 binding site induced gel shift in EMSA (Fig. 2A). Complex formation is specific since it can be eliminated using unlabeled oligonucleotide in excess. SP1 supershift after incubation with SP1 antibody is shown in Fig. 2A, lane 6. The same labeled oligonucleotide, but mutated in SP1 binding site is not capable of forming the SP1/IRS2 promoter transcription complex (Fig. 2A, lane 8). A longer DNA fragment containing the NFI and the SP1 binding site was used in EMSA as well (Fig. 2B). This oligonucleotide also generates a shift band that disappears after competitive incubation with unlabeled oligonucleotide.

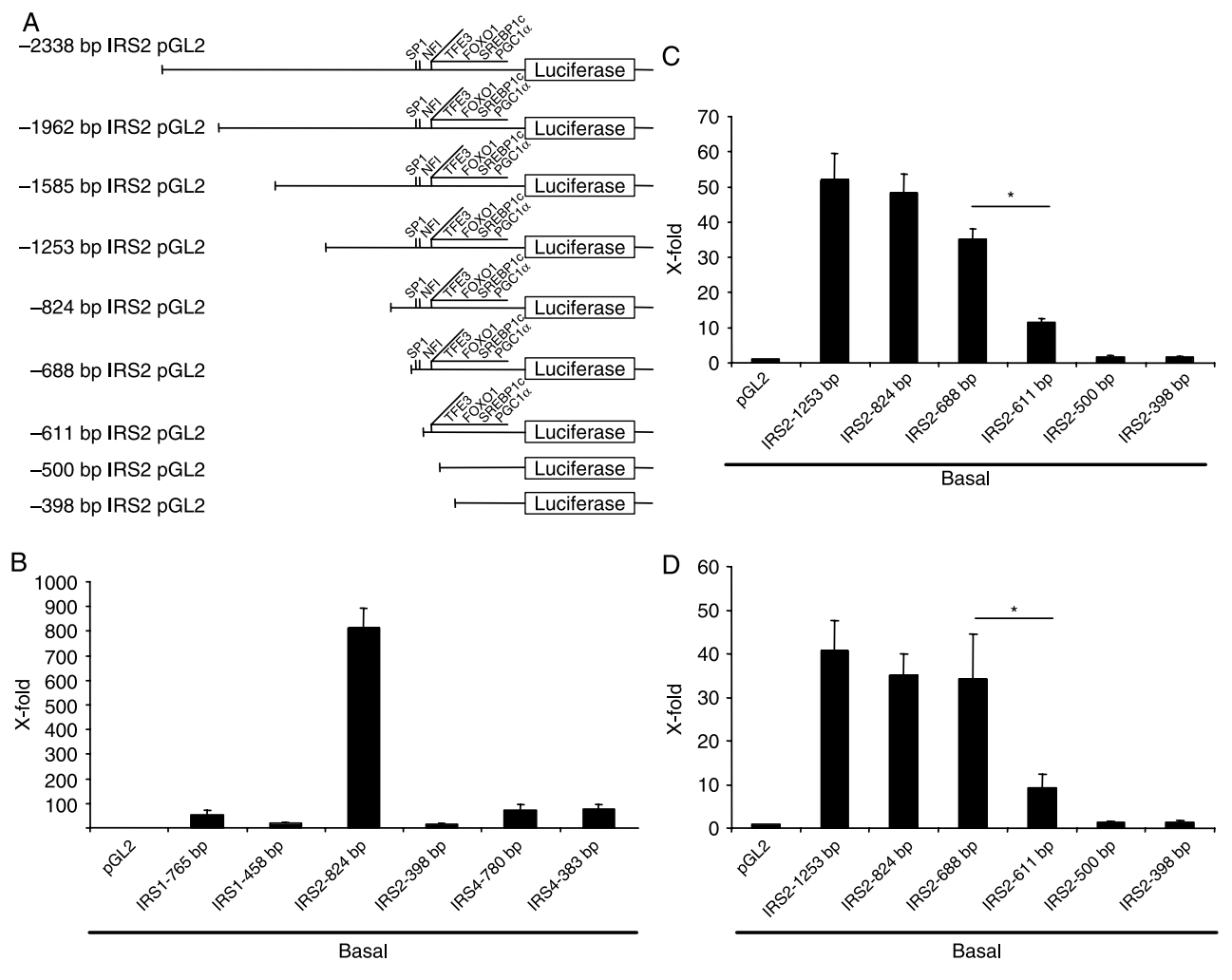

Figure 1 IRS2 promoter reporter constructs and assays in human hepatocellular carcinoma cells (HepG2, $\mathrm{HuH7}$ ). (A) IRS2 promoter reporter constructs in pGL2, getting shorter from distal were used in the present study. (B) Comparison of basal IRS1/-2/-4 promoter activity in HepG2 cells. (C) Isolation of the main activating regions in the IRS2 promoter using promoter deletion constructs, shortened stepwise from upstream. (D) HuH7 hepatocellular carcinoma cells were transfected with IRS2 promoter deletion constructs for comparison. Data are means \pm s.D. $\left({ }^{*} P<0 \cdot 001\right.$, unpaired Student's $t$-test). 
However, the oligonucleotide mutated in the SP1 binding motive is still capable of producing a shiftband supershift using SP1 antibody (lane 10) even though this fragment does not contain another SP1 binding site. Therefore, SP1 participates in the IRS2 promoter transcription complex not only by direct DNA binding, but also by indirect binding to other factors within the promoter transcription complex. Otherwise SP1 could not remain in the complex and cause supershift with the mutated oligonucleotide.

To verify NFI binding in this promoter region, HepG2 nuclear extracts were incubated with an oligonucleotide containing the potential NFI binding site of IRS2 promoter. The shifted band occurring in EMSA was suppressed by incubating with unlabeled fragment. Incubation with NFI antibody does not give rise to a supershift but the usual shift band starts to disappear. Consequently, NFI is part of the complex and the NFI antibodies might disturb formation of the DNA/transcription factor complex (Fig. 2C, lane 6).

SP1 and NFI binding to the promoter region suggested in the previous experiments was verified using ChIP assay (Shang et al. 2000). HepG2 cells were fixed, DNA was sonicated and protein/DNA complexes were immunoprecipitated with SP1 antibody or NFI antibody and an unspecific antibody to control for unspecific binding. Bound DNA fragments were washed and purified, and PCR was done with specific primers. As a control for the PCR reaction, sonicated DNA was used, which was not incubated with any antibody. The ChIP assay confirmed SP1 and NFI binding to the DNA (Fig. 2D). As a positive control, we used IP with an RNA polymerase II antibody followed by GAPDH PCR. Thus, ChIP assays could verify binding of

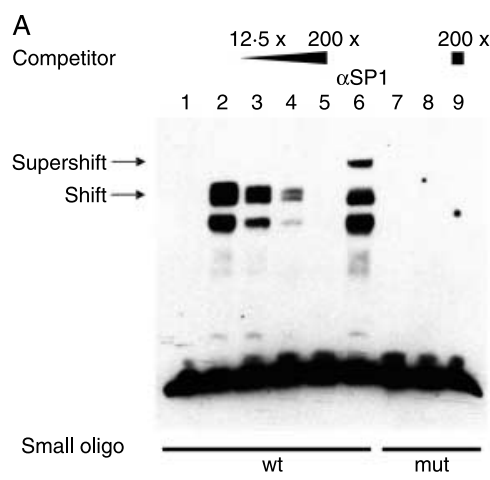

B
Competitor

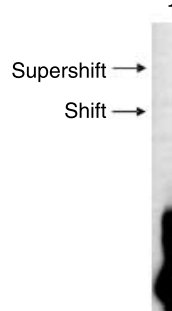

Large oligo

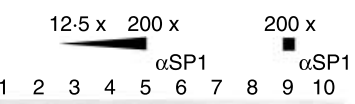

$\begin{array}{lllllllll}2 & 3 & 4 & 5 & 6 & 7 & 8 & 9 & 10\end{array}$

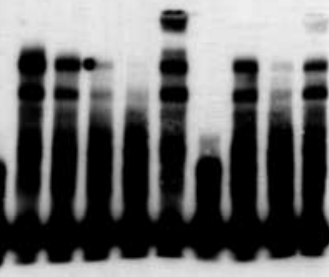

$$
\text { go }
$$

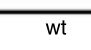

D
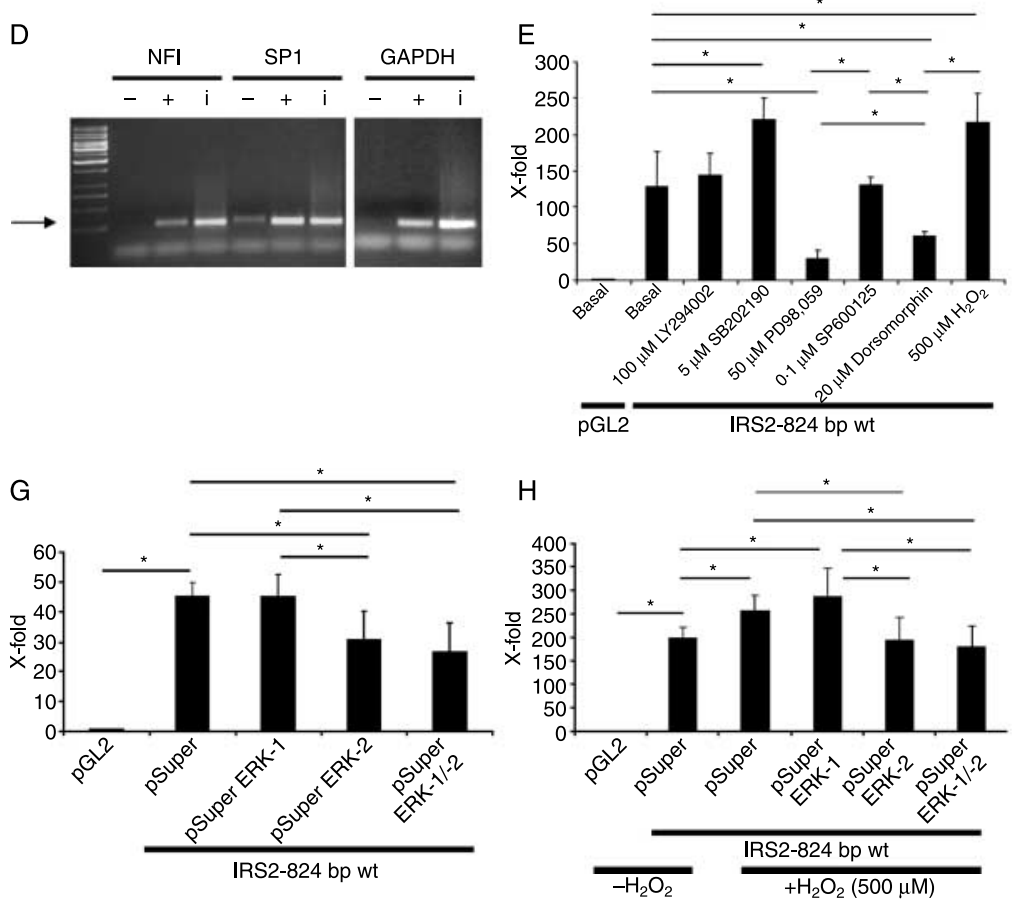

C

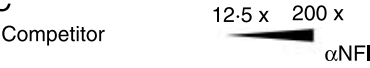

$\begin{array}{llllll}1 & 2 & 3 & 4 & 5 & 6\end{array}$
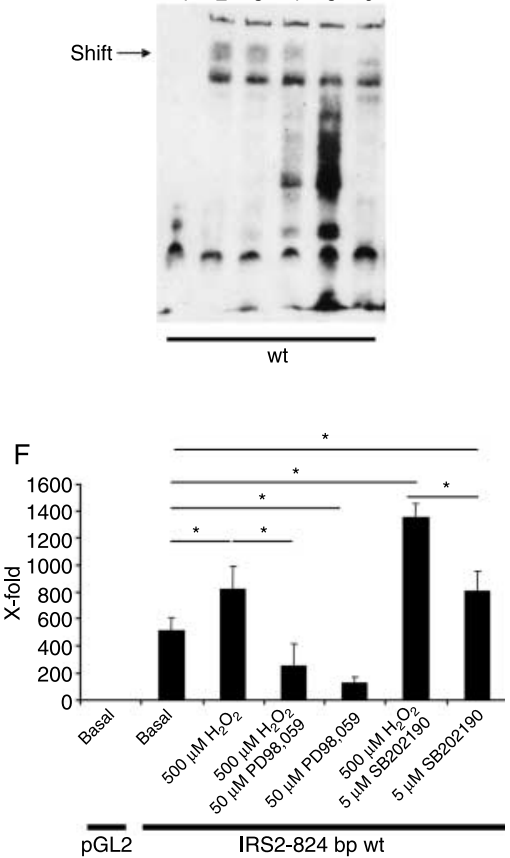

I

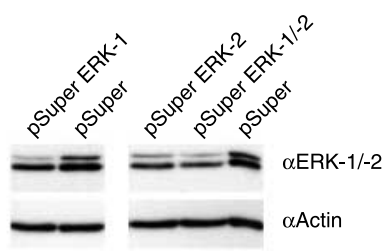


SP1 and NFI to the postulated sites on the IRS2 promoter in vivo (Supplementary Fig. 1, see section on supplementary data given at end of this article).

\section{Oxidative stress activates IRS2 transcription}

To identify possible signaling pathways that activate IRS2 transcription we incubated HepG2 cells, which were transfected with IRS2-824bp-pGL2 with inhibitors of different key kinases (Fig. 2E). The PI3-kinase inhibitor LY294002 decreased promoter activity slightly whereas the inhibition of ERK using the MEK-1 inhibitor PD98,059 reduced basal promoter activity much more strongly. In contrast, using the p38MAPK inhibitor SB202190, IRS2 promoter activity nearly doubles (Fig. 2E). We also found a 50\% reduction of IRS2 promoter activity in luciferase assays if the stress activated kinase AMPK was inhibited by dorsomorphin (Fig. 2E). Since reactive oxygen species have been discussed in the pathogenesis of HCC as well as the associated upregulation of drug resistance gene expression (Tien \& Savaraj 2006) and as a cause of insulin resistance, we used $\mathrm{H}_{2} \mathrm{O}_{2}$ to induce oxidative stress. $\mathrm{H}_{2} \mathrm{O}_{2}$ activates ERK in HepG2 cells for over $30 \mathrm{~h}$ and preincubation with $50 \mu \mathrm{M}$ PD98,059 abolished the effect completely (Fig. 2F). To ensure effective working of the inhibitors under the used experimental conditions, we performed western blots with phosphospecific antibodies as shown in Supplementary Fig. 2A, see section on supplementary data given at end of this article.
Basal promoter activation doubled after stressing the cells with $500 \mu \mathrm{M} \mathrm{H}_{2} \mathrm{O}_{2}$. The signal rose even further after coincubation with the p38MAPK inhibitor SB202190 (Fig. 2F). Furthermore, there was an activation of IRS2 promoter after incubation with SB202190 alone that was just as high as the induction with $\mathrm{H}_{2} \mathrm{O}_{2}$. In conclusion, both effects on the promoter are additive. After inhibition of ERK with $50 \mu \mathrm{M}$ PD98,059, basal promoter activity was downregulated by $87 \%$. In the case of oxidative stress induced promoter activity, inhibition of ERK yields in signal reduction by $75 \%$. Given that the identification of ERK signaling as primary stress induced regulator of IRS2 might be a key aspect of basal and stress induced IRS2 transcription, we performed additional experiments for specification. HepG2 cells were transfected with siRNA expression constructs to downregulate ERK-1, ERK-2, or both. Afterwards cells were transfected with IRS2824bp-pGL2 to investigate promoter activation (Fig. 2G and $\mathrm{H}$ ). Surprisingly, reduced ERK-1 expression alone was not sufficient to decrease basal or $\mathrm{H}_{2} \mathrm{O}_{2}$ stimulated IRS2 promoter activity (Fig. 2H and I). Interestingly, knocking down ERK-2 alone or together with ERK-1 impaired basal and abolished $\mathrm{H}_{2} \mathrm{O}_{2}$ stimulated IRS2 promoter activity. Therefore, IRS2 promoter activation might be mainly dependent on ERK-2. However, there are certain limitations to the siRNA approach used in the present study since only a partial knockdown of the ERK-1 and -2 was achieved and the used siRNA targeting ERK-2 slightly reduced ERK-1 expression in the present experiments as well (Fig. 2I).

Figure $2 \mathrm{NFI}$ and SP1 bind to the IRS2 promoter. (A) For investigation of SP1 binding $8 \mu$ g nuclear extracts (NE) derived from HepG2 cells incubated for $30 \mathrm{~h}$ without serum were used in EMSA. Biotinylated double-stranded oligonucleotides were incubated without (lane 1) and together with NE to achieve band shift (lane 2). Specificity of oligonucleotide binding to whole complex was verified using unbiotinylated oligonucleotide in 12.5-, 50- and 200-fold molar excess (lane 3-5) for displacement of the biotinylated oligonucleotides. Participation of SP1 in shiftband was verified using specific antibodies for induction of supershift (lane 6). Biotinylated oligonucleotides mutated in the SP1 binding site were incubated without (lane 7) or together with NE (lane 8). Biotinylated oligonucleotides were replaced by incubation with unbiotinylated oligonucleotides in 200-fold molar excess (lane 9 ). Band shift and supershift are indicated by arrows. (B) Larger oligonucleotide containing the SP1 and NFI binding site (wt) was used for band shift. In case of incubation with the mutated oligonucleotide only the SP1 binding site was mutated (mut). NFI binding site was unchanged. Supershift was induced using SP1 antibodies (lane 6, 10). (C) An oligonucleotide containing only the NFI binding site was used. Incubation without (lane 1) and with NE (lane 2) to achieve band shift were performed. Specificity of oligonucleotide binding to the complex was proven using unbiotinylated oligonucleotide in 12.5-, 50- and 200-fold molar excess (lane 3-5) for competitive binding. To achieve supershift incubation with NFI antibodies was performed (lane 6). (D) For verification of binding in ChIP assays HepG2 cells were fixated with formaldehyde, nuclear DNA was prepared and after sonication fragmented and crosslinked DNA was incubated with antibodies against SP1, NFI, or RNApol II. After immunoprecipitation, decrosslinking and DNA purification postulated binding region was localized via specific PCR primers. GAPDH primers were used for RNApol II control reaction. IP was done with unspecific antibody $(-)$ of same isotype and specific antibody $(+)$ against SP1, NFI, or RNApol II. Total sonicated, decrosslinked DNA was used as positive input control (i) for PCR. Product of expected size is indicated by arrow. (E) Influence of PI3-kinase (LY294002), MAPK pathway (PD98,059, SB202190), JNK (SP600125), and AMPK (Dorsomorphin) inhibition on IRS2 promoter activity. Also stimulation with $\mathrm{H}_{2} \mathrm{O}_{2}$ is shown. (F) Basal and induced IRS2 promoter activity using $500 \mu \mathrm{M} \mathrm{H}_{2} \mathrm{O}_{2}$ is inhibited through ERK inhibitor PD98,059. p38MAPK inhibitor alone induces activity nearly twofold and even threefold after coincubation with $500 \mu \mathrm{M} \mathrm{H}_{2} \mathrm{O}_{2}$. (G) Dual luciferase promoter reporter assays were done in HepG2 cells after ERK-1, ERK-2, or both were downregulated using siRNA expression plasmids. $(H)$ Cells were treated as in $G$ and stimulated additionally with $\mathrm{H}_{2} \mathrm{O}_{2}$. (I) HepG2 cells were transfected with siRNA expression constructs as indicated to prove ERK downregulation by western blot. Dual luciferase reporter experiments were done in triplicate. Quantification represents six independent experiments. Data are means \pm S.D. ( ${ }^{\star} P<0 \cdot 001$, unpaired Student's $t$-test). 
Furthermore, we were able to show by western blot, that ERK phosphorylation is enhanced after inhibition of p38MAPK in combination with $\mathrm{H}_{2} \mathrm{O}_{2}$ stimulation (Supplementary Fig. 2B). Consequently, basal and oxidative stress induced IRS2 promoter activity in HepG2 cells are mainly dependent on ERK activity and modulated by p38MAPK.

\section{ERK induces endogenous IRS2 expression}

To prove induction of endogenous IRS2 by oxidative stress, we incubated HepG2 cells for $30 \mathrm{~h}$ with rising concentrations of $\mathrm{H}_{2} \mathrm{O}_{2}$. Afterwards total RNA was extracted, and RT-PCR was performed with IRS2 specific primers. RNA expression was normalized on GAPDH expression. There was a concentration dependent two- to threefold increase of IRS2 expression (Fig. 3A, upper left), which matches our luciferase reporter assays. Enhanced IRS2 expression after incubation with rising $\mathrm{H}_{2} \mathrm{O}_{2}$ concentrations could be turned off with PD98,059 (Fig. 3A, right). Consequently, oxidative stress-induced IRS2 expression is regulated by ERK in vivo.

We performed EMSA to show that SP1 binding in the identified activating region of the IRS2 promoter is dependent on ERK activity (Fig. 3B). We treated HepG2 cells with or without $500 \mu \mathrm{M} \mathrm{H}_{2} \mathrm{O}_{2}$ together
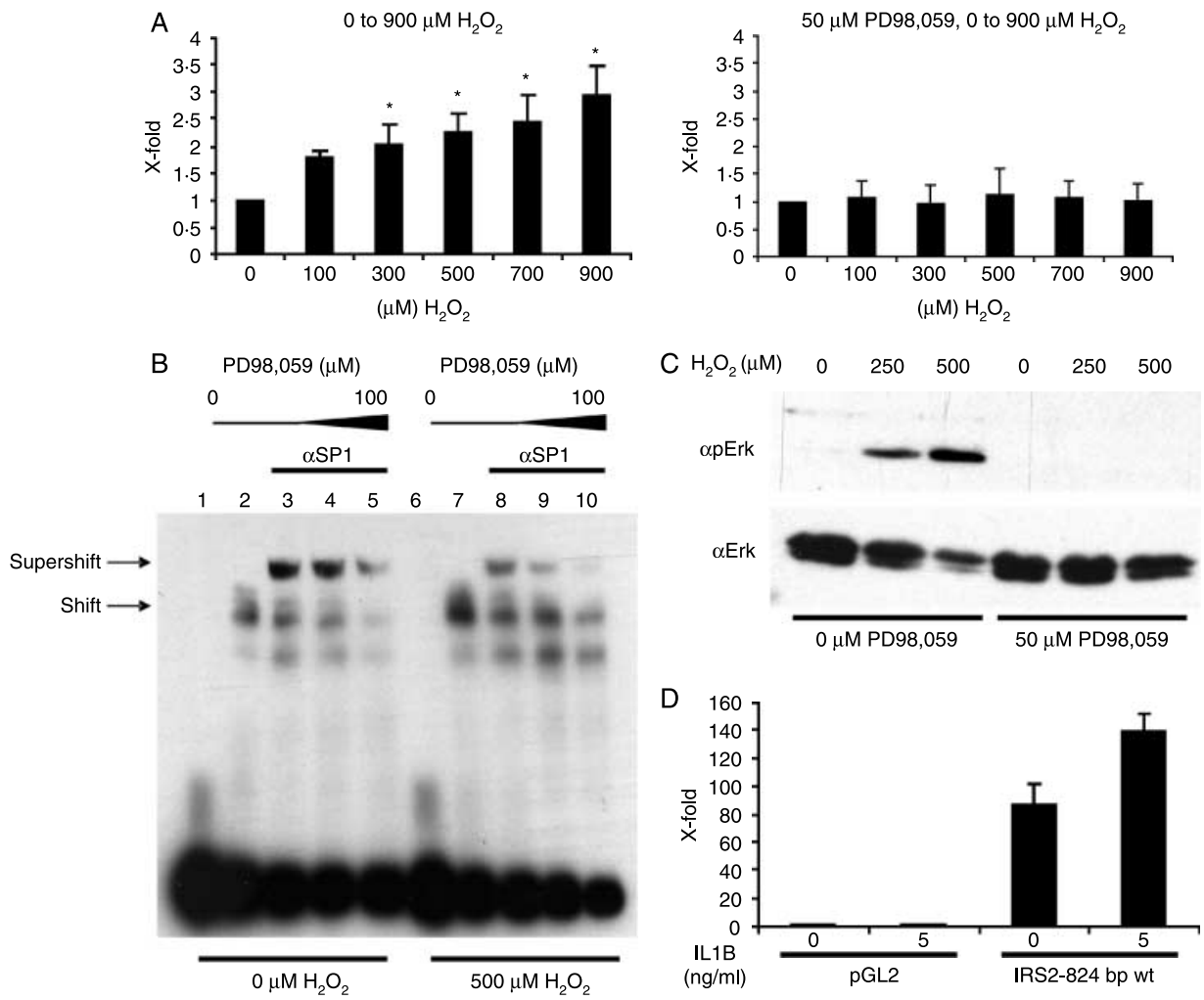

Figure 3 Oxidative stress induces endogenous IRS2 transcription via ERK activation in HepG2 cells. (A) Cells were stimulated with rising concentrations of $\mathrm{H}_{2} \mathrm{O}_{2}$. RNA was prepared and RT-PCR was performed using primers specific for IRS2 as shown on the left. Furthermore, cells were starved and stimulated with rising concentrations of $\mathrm{H}_{2} \mathrm{O}_{2}$, but were incubated additionally with $50 \mu \mathrm{M}$ PD98,059 as shown on the right. All IRS2 RT-PCRs were done in parallel with primers specific for GAPDH for normalization. Quantification represents five independent experiments. Data are means \pm S.D. $\left({ }^{\star} P<0 \cdot 05\right)$. (B) SP1 starts disappearing from supershift band with ascending ERK inhibitor concentration in EMSA. PD98,059 treated cells were starved (lane 1-5) or starved and stimulated with $500 \mu \mathrm{M} \mathrm{H}_{2} \mathrm{O}_{2}$ (lane 6-10). All samples were incubated with biotinylated double-stranded oligonucleotide including SP1 and NFI binding sites. Supershift was induced using SP1 antibody (lane $3-5,8-10)$. Biotinylated oligonucleotides were incubated without NE in lane 1 and 6 . (C) For verification of prolonged ERK phosphorylation HepG2 cells were treated for $30 \mathrm{~h}$ with $\mathrm{H}_{2} \mathrm{O}_{2}$. Effect of ERK inhibition was verified by preincubating the cells for $3 \mathrm{~h}$ with PD98,059 before $\mathrm{H}_{2} \mathrm{O}_{2}$ stimulation. After that total lysates were separated on SDS-PAGE and western blot was done with the indicated antibodies. (D) HepG2 cells were transfected with IRS2-824bp-pGL2 promoter reporter luciferase construct and empty vector and were treated for $30 \mathrm{~h}$ with or without IL1B. 
with rising amounts of MEK-1 inhibitor PD98,059 (Fig. 3B and G). Nuclear extracts were made and incubated with the SP1/NFI binding site containing labeled oligonucleotide (lane 2, 7) plus SP1 antibody (lane 3-5, 8-10) to achieve supershift. SP1 participation in the supershift band decreased with increasing inhibitor concentration (Fig. 3B). Thus, SP1 binding to the IRS2 promoter is regulated by ERK activation. In order to test if other factors activating the MAPK pathway have similar effects on the IRS2 promoter we incubated HepG2 cells transfected with IRS2 luciferase reporter constructs with IL1B. Consistent with our previous results IL1B treatment increased IRS2 promoter activity (Fig. 3D).

\section{NFI or SP1 is essential for IRS2 promoter activity}

To investigate the function of NFI and SP1 in stressinduced activation of IRS2 we used the IRS2-824bpNFImut-pGL2 and IRS2-824bp-SP1mut-pGL2 mutants and transfected each in HepG2 cells (Fig. 4A and B). As described above, basal promoter activity was influenced only slightly by single mutations. The NFI mutant promoter induction with $\mathrm{H}_{2} \mathrm{O}_{2}$ showed only a minor reduction of promoter activity and the luciferase signal still increased by inhibition of p38MAPK (Fig. 4A). The same was observed for the IRS2-824bp-SP1mut-pGL2 mutant (Fig. 4B). Finally, the NFI/SP1 binding site double mutant could not be stimulated with $\mathrm{H}_{2} \mathrm{O}_{2}$ or with SB202190 (Fig. 4C). We found no change in SP1 or NFI protein expression under the used conditions (Supplementary Fig. 2C). Hence, both SP1 and NFI mediate stress-induced activity of IRS2 promoter via ERK.

\section{Transcriptional regulation of IRS proteins is promoter- and cell type specific}

In order to elucidate whether the effects mediated by the identified region of the IRS2 promoter are hepatoma cell and IRS2 promoter specific we investigated different cell types and the IRS1 and -4 promoter.

The human IRS1 promoter constructs showed a completely different activation profile in HepG2 cells in luciferase reporter assays compared to the IRS2 promoter under the same conditions. The highest activity was only measured with the largest fragment of the promoter, and decreased substantially after cutting off the first $487 \mathrm{bp}$ from distal (Fig. 5A, left). The IRS4 promoter appeared to have moderate activity levels that could not be diminished even after cutting down the promoter to $-383 \mathrm{bp}$ (Fig. 5A, right). Both promoters activity in human hepatoma cells was weak in comparison to the IRS2 promoter (Fig. 1B). Concerning cell specificity we could show that the IRS2 promoter was
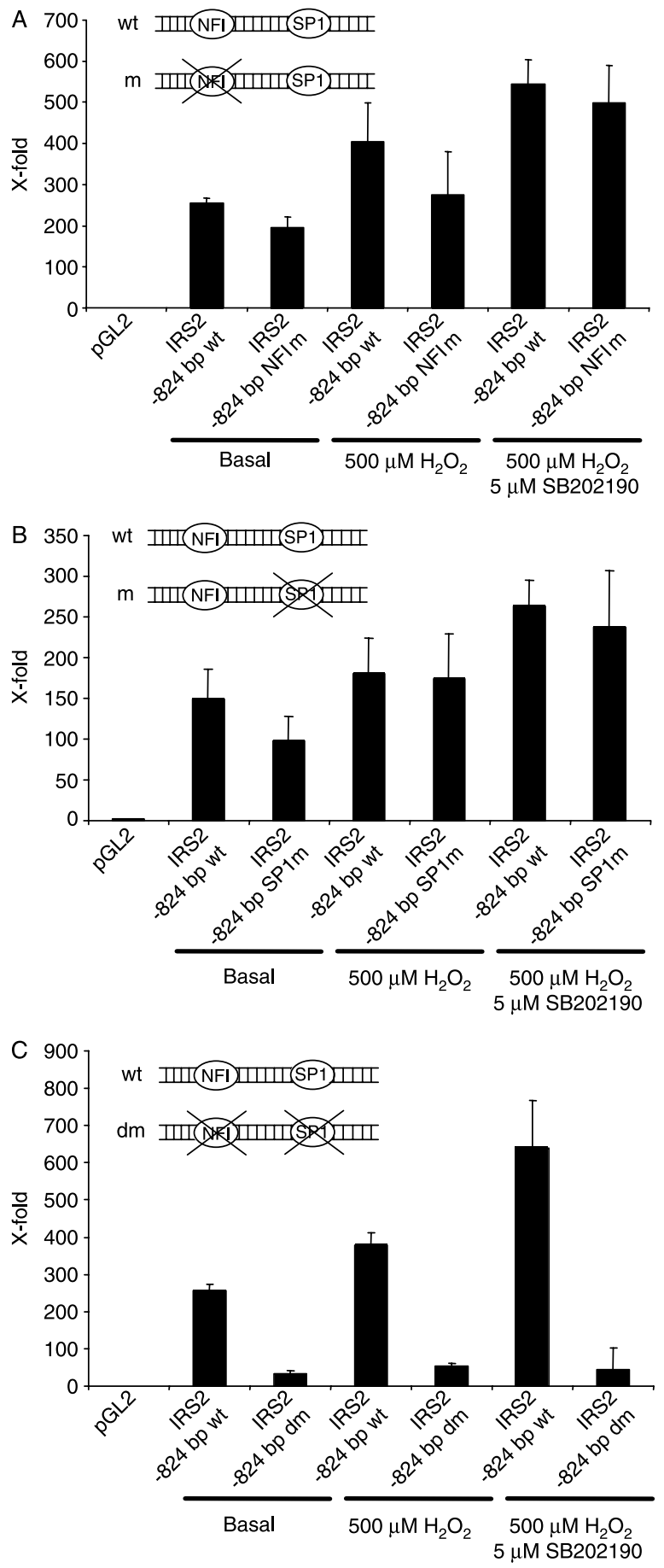

Figure 4 Dual luciferase reporter assays using IRS2 promoter constructs mutated in NFI-/SP1-binding sites in HepG2 cells. (A) Cells were transfected with IRS2-824bp-pGL2 wt and with the same plasmid mutated only in NFI binding site. (B) Cells were treated as in A but the IRS2-824bp-pGL2 plasmid mutated in SP1 site or C, the IRS2-824bp-pGL2 construct double mutated in NFI and SP1 binding site was used. All cells were kept $30 \mathrm{~h}$ serum free prior to measurement. Treatments were done as indicated. 

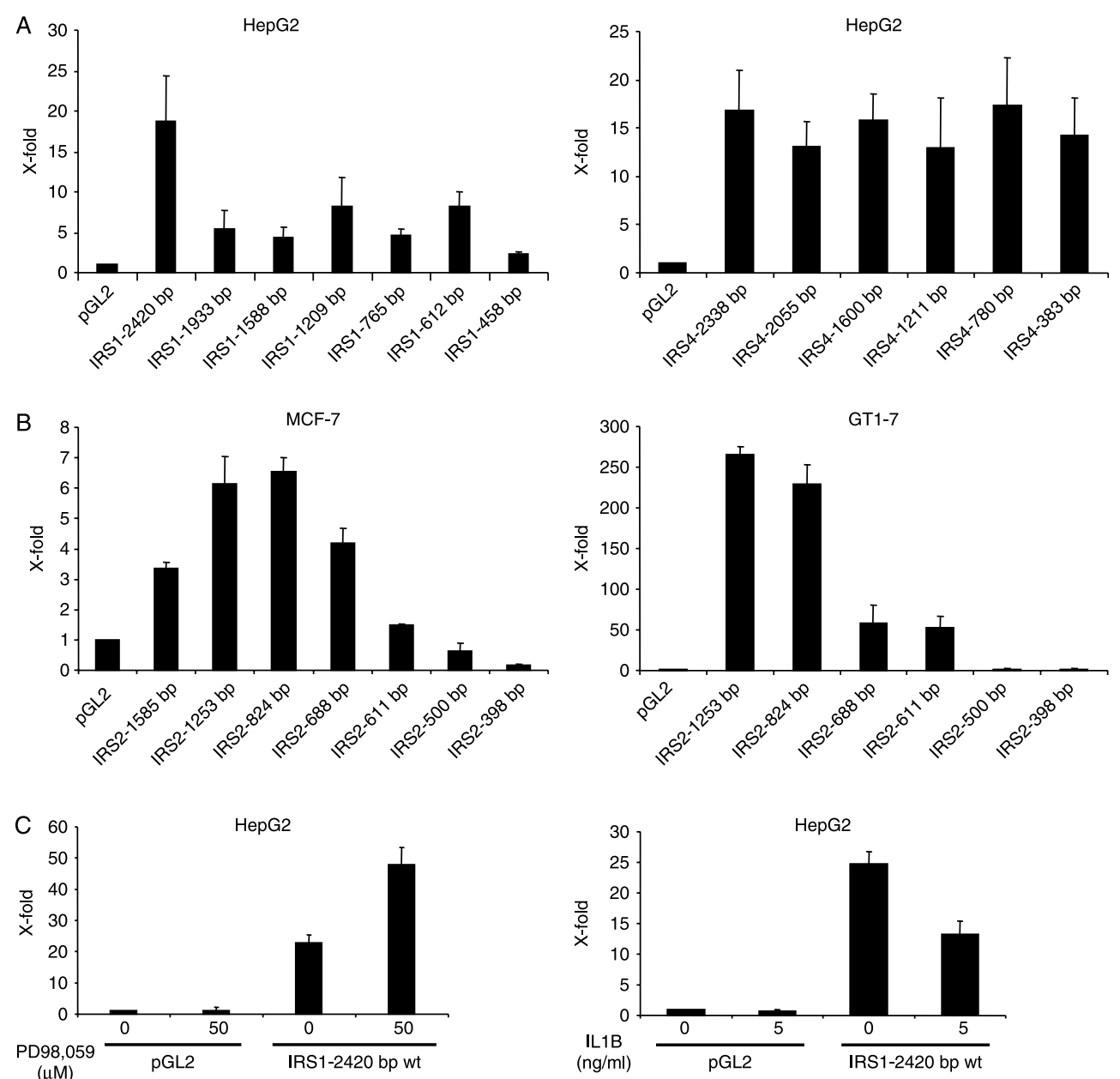

Figure 5 Activation of IRS2 promoter in HepG2 cells is promoter and cell specific. (A) IRS1/-4 promoter reporter constructs in pGL2, getting shorter from distal were transfected in HepG2 cells and luciferase assays were performed. (B) To show tissue specificity of IRS2 promoter activity, IRS2 promoter reporter constructs were transfected in MCF-7 and GT1-7 cells. (C) To show effects of ERK inhibition and IL1B incubation on IRS1 promoter, HepG2 cells were transfected with IRS1-2420bp-pGL2 promoter reporter luciferase construct and empty vector. Cells were treated with or without PD98,059 (left) and with or without IL1B for $30 \mathrm{~h}$ (right).

only weakly active in MCF-7 cells, which are often used as a cell culture model for breast cancer. Although the activation profile of the deletion constructs in these cells is different (Fig. 5B, left), it revealed an activity drop in the same IRS2 promoter region $(-688$ to $-611 \mathrm{bp}$ ) as in human hepatoma cells, suggesting that this promoter region might be important in other cancer cells as well. In contrast, IRS2 promoter showed high expression in hypothalamic neuron cells (GT17). IRS2 promoter activity in these cells is comparable to that observed in HepG2 cells, but the major activating region in GT17 cells identified after deleting the promoter from distal lies between -824 and $-688 \mathrm{bp}$ and not between -688 and $-611 \mathrm{bp}$ (Fig. 5B, right). HuH7 hepatocellular carcinoma cells presented with the same IRS2 promoter activation pattern as HepG2 cells do. These data suggest that the promoter regulation of different IRS-proteins is highly cell type and IRS-promoter specific.

\section{Opposite effects on IRS2 and $\mathbf{- 1}$ promoter activity induced by ERK inhibition and IL1B stimulation}

As described above, IL1B nearly doubled IRS2 promoter activity in HepG2 cells. To prove specificity of this activation we also stimulated HepG2 cells transfected with the largest IRS1 promoter construct. IRS1 promoter activity fell about $50 \%$ after IL1B stimulation (Fig. 5C, right). In the case of ERK inhibition the IRS1 promoter showed a twofold increased activity (Fig. 5C, left). Thus, ERK activity and IL1B stimulation have opposite effects on IRS1 and -2 promoter. 


\section{Effects of glucose and PPAR $\gamma$ on IRS2 promoter}

In primary pancreatic $\beta$-cells and adipocytes a transcription activation of the IRS2 promoter dependent on glucose concentration has been described (Lingohr et al. 2006). To test possible activating effects of glucose on our luciferase reporter plasmid, we transfected HepG2 cells with the IRS2-824bp-pGL2 plasmid. As shown in Fig. 6A there is no such effect in our system. We stimulated these cells $12 \mathrm{~h}$ after transfection with $25-400 \mathrm{mg} / \mathrm{dl}$ glucose and there was no significant change in IRS2 promoter activity. In conclusion, glucose seems not to influence IRS2 transcription in liver.

In 3T3-L1 adipocytes, thiazolidinediones induced expression of the IRS2 gene through PPAR $\gamma$ activation (Smith et al. 2001). In our hands we could not find any activating effects of rosiglitazone using our IRS2
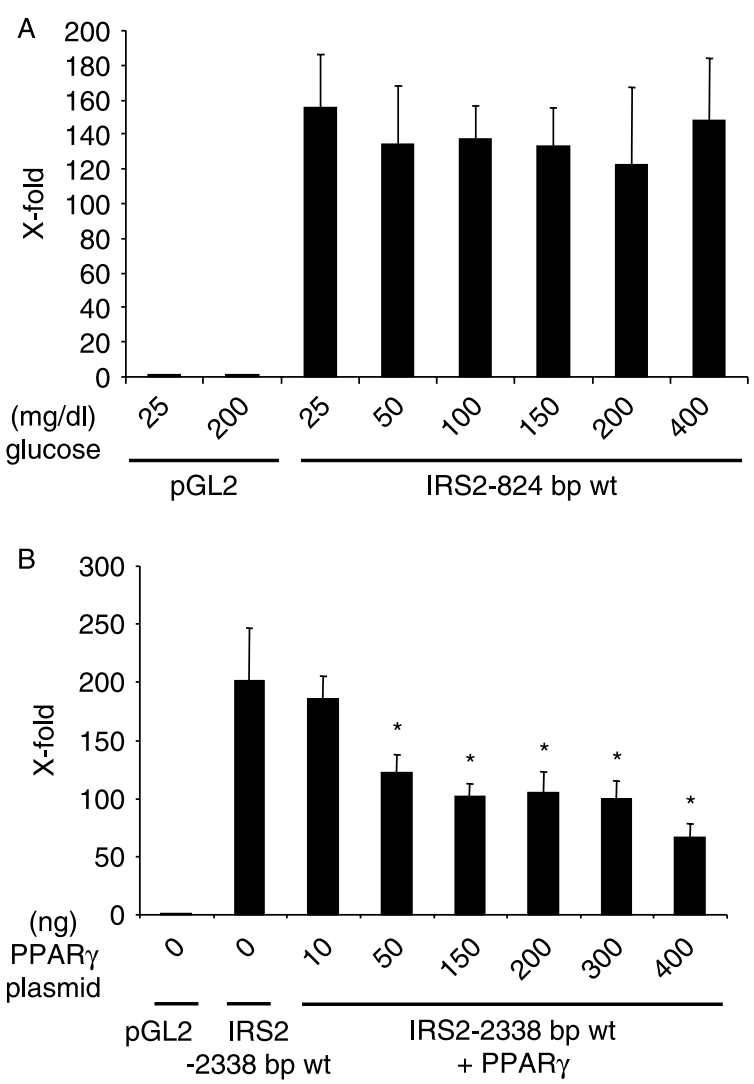

Figure 6 Effect of glucose and PPAR $\gamma$ on IRS2 promoter in dual luciferase reporter assay. (A) HepG2 cells were transfected with IRS2-824bp-pGL2 plasmid, and were stimulated with rising concentrations of glucose $(25-400 \mathrm{mg} / \mathrm{dl})$ for $30 \mathrm{~h}$. (B) Effect of PPAR $\gamma$ on IRS2 promoter. HepG2 cells were transfected with fulllength IRS2-2338bp-pGL2 plasmid together with a rising amount of pCMX PPAR $\gamma(10-400 \mathrm{ng})$ for constitutive PPAR $\gamma$ expression. DNA amount used for transfection was kept constant using pcDNA3.1 empty vector. Data are means \pm s.D. $\left({ }^{\star} P<0.001\right.$, unpaired Student's $t$-test). promoter reporter plasmids (data not shown). Consequently, we cotransfected IRS2-2338bp-pGL2 transfected HepG2 cells with a PPAR $\gamma$ expressing plasmid (pCMX PPAR $\gamma$ ) and found that there was a decrease in luciferase activity with a rising amount of PPAR $\gamma$ (Fig. 6B). Thus, in liver, PPAR $\gamma$ might function as an inhibitor of IRS2 transcription and not as an activator.

\section{Discussion}

The insulin receptors and IGF1R are tyrosine kinases that mediate phosphorylation of the IRS (Yamada et al. 1997). Both IRS1 and -2 are widely expressed, including the liver (Sun et al. 1992, 1995). Phosphorylated IRS proteins activate multiple signaling pathways, e.g. the PI3-kinase and MAPK cascades that directly regulate various physiological processes (Saltiel \& Kahn 2001). Activation of the PI3-kinase/Akt cascade promotes growth and survival by phosphorylation of FOXOtranscription factors to regulate gene transcription and phosphorylation of Bcl-2-associated death protein to inhibit apoptosis (Cross et al. 1995). Akt inactivates GSK-3 $\alpha / \beta$ which promotes cellular metabolism, proliferation, and survival (Cross et al. 1995). Since IRS2 regulates hepatic glucose metabolism and is frequently overexpressed in human HCC (Boissan et al. 2005), we aimed to identify mechanisms that regulate the transcription of the IRS2 gene promoter in human HepG2 cells. After starting with the $\sim 2.3 \mathrm{~kb}$ IRS2 promoter, we were able to isolate a fragment of the promoter that is responsible for $87 \%$ of total basal promoter activity. In HepG2 cells IRS2 promoter activity was much stronger than IRS1 and -4 promoter activity. Therefore, we focused on revealing regulatory mechanisms of the IRS2 promoter. Nakagawa et al. (2006) who worked with a truncated IRS2 promoter in HepG2 cells described a sequence in the promoter that is located closer to the translation start codon compared to our findings. FOXO1 and TFE3 are able to bind in this region resulting in promoter activation (Nakagawa et al. 2006). The authors also showed that SREBPs could inhibit this activation. In the present study we were able to verify this region as important for IRS2 transcription. However, Nakagawa et al. (2006) used a smaller part of the promoter that was shorter than -611 bp referring to the translation start site, explaining why Nakagawa et al. have missed the region described in the present study. By investigating larger promoter fragments, we were able to identify another region in the IRS2 promoter responsible for an even higher activation of IRS2 transcription than that achieved by TFE3.

We focused on the identification of transcription factors that are able to bind to the $77 \mathrm{bp}$ fragment that has been identified in our luciferase reporter 
studies and confirmed SP1 and NFI binding. SP1 has been described as an activator of many genes (Suske 1999). With respect to insulin/IGF1R signaling it has been shown that SP1 is also involved in the regulation of the insulin receptor gene itself (Foti et al. 2003) as well as the IGF1R gene (Maor et al. 2006). Since there are multiple potential binding sites for SP1 in the IRS2 promoter, Vassen et al. (1999), the authors of the first description of the human IRS2 promoter sequence speculated about a major role for SP1 in the transcriptional regulation of the IRS2 gene (Vassen et al. 1999). One of the major signaling cascades that activates SP1 is the MAPK pathway leading to ERK activation and SP1 phosphorylation (Merchant et al. 1999). Furthermore, overexpression and hyperphosphorylation of ERK is detected in 80-90\% of HCCs (Huynh et al. 2003), and inhibition of ERK induces HCC growth suppression (Huynh et al. 2007). Therefore, we speculated that this region is regulated by the MAPK pathway. The MEK-1 inhibitor PD98,059 abolished IRS2 promoter activity, suggesting a major role of this signaling pathway in regulating IRS2 expression in human liver cells. The siRNA experiments performed in the present study might suggest that this IRS2 promoter activation is mainly dependent on ERK-2.

NFI binds to a consensus element that is often found in a close relationship to other transcription factor binding sites and is able to work as an activator (Jones et al. 1987) or repressor (Szabó et al. 1995) of transcription. We assumed that NFI might function as a repressor of the IRS2 gene promoter that would interfere with the activator function of SP1 as it has been described for the poly(ADP-ribose) polymerase-1 promoter (Laniel et al. 2001) or the platelet-derived growth factor A promoter (Rafty et al. 2002). However, our experiments prove that SP1 or NFI binding is sufficient to activate the promoter. The single mutant reporter constructs showed just a small decrease in basal activity as previously shown for other promoters (Darne et al. 1997), and were still inducible by oxidative stress and the p38MAPK inhibitor SB202190. In conclusion, disrupting only one site had just a slight effect on the promoter. Interestingly, in the double mutant promoter basal activity was almost completely abolished, and $\mathrm{H}_{2} \mathrm{O}_{2}$ or SB202190 activation of the promoter was diminished. Consequently, both transcription factors work together in one complex to activate the IRS2 gene promoter similar to the vas deferens protein promoter (Darne et al. 1997). The short oligonucleotide containing a mutation in the SP1 binding site that destroys binding completely was unable to produce a shift or supershift in EMSA. However, the same oligonucleotide lengthened to the NFI site, but mutated in SP1 binding site, produced a clearly visible SP1 supershift suggesting

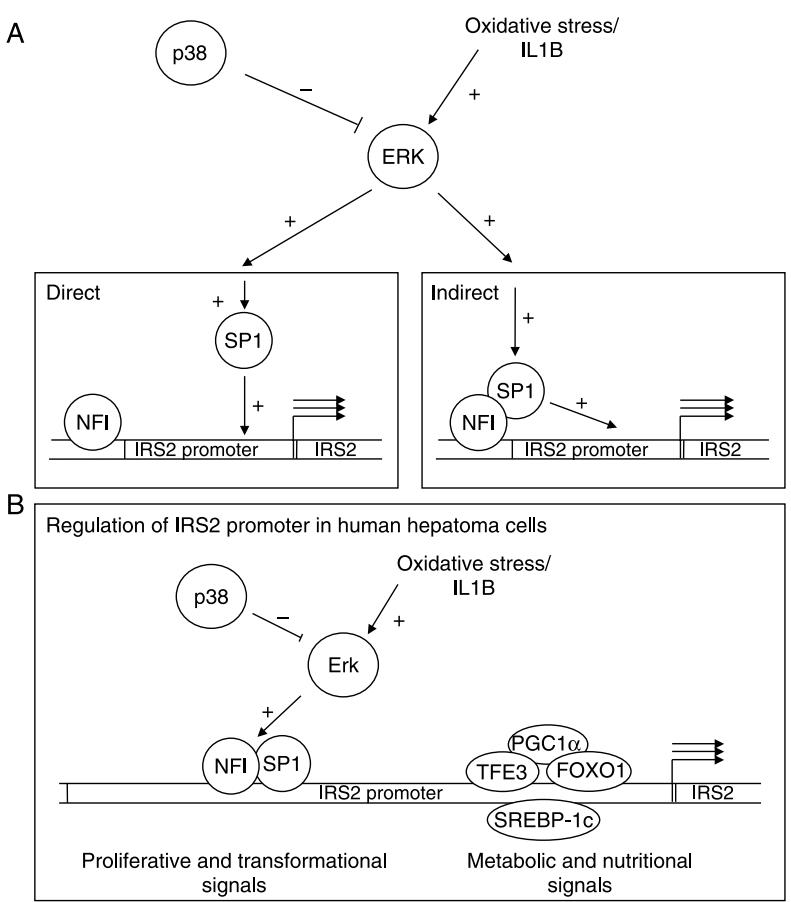

Figure 7 Promoter activation model of the human IRS2 promoter in human hepatoma cells. (A) SP1 or NFI is essential for IRS2 promoter activation. This activity is modulated by members of the MAPK cascade. Oxidative stress induces IRS2 transcription and inhibition of ERK activity leads to a decrease of stress induced and basal promoter activity. p38MAPK inhibition increases ERK activation as well as basal and stress mediated activation of the promoter. SP1 or NFI binding is essential to activate the promoter. If SP1 binding to the promoter is eliminated, e.g. after mutation of the binding site, binding of SP1 to the transcriptional complex can be restored through NFI. NFI recruits SP1 indirectly to participate in the transcription complex, even if SP1 cannot bind to DNA directly. (B) Our study suggests a novel model for the organization of the IRS2 promoter. The described region of the IRS2 promoter located -688 to -611 bp from the translational start is predominantly targeted by ERK mediated signals suggesting a role for proliferation and tumorigenesis. This region lies about $100 \mathrm{bp}$ upstream of the previously described locus of the IRS2 promoter responsible for the metabolic feedback.

that NFI itself or by recruiting another factor is capable of directing SP1 to the IRS2 promoter (Fig. 7A). This is consistent with our observations using the NFI/SP1 double mutation in luciferase reporter assays proving that only mutation of both sites deactivates the promoter completely.

In the present study, we show that basal transcription of IRS2 promoter in HepG2 cells increased two- to threefold after oxidative stress in luciferase reporter assays. As proof of principle we were able to obtain similar observations on endogenous IRS2 expression in HepG2 cells. Certain IL1B polymorphisms, which might be associated with high IL1B production in liver, serve as genetic markers for HCC development in 
patients with chronic hepatitis B and C (Tanaka et al. 2003, Hirankarn et al. 2006). Therefore, we tested the effect of IL1B on IRS2 promoter activity. According to our observation using the MAPK inhibitor PD98,059, IL1B increased IRS2 promoter activity to a similar extent as oxidative stress. These results provide the molecular link between the expression of inflammatory cytokines like IL1B and increased IGF1R signaling observed in HCC. A novel mechanism of cross-talk between IGF1 and EGF has been found with regard to breast cancer cell migration (Cui et al. 2006). EGF induced upregulation of IRS1 expression by both ERK and JNK pathways, but IRS2 expression was only up-regulated by JNK. In our experiments, although dealing with cancer cells, ERK is the main activator of IRS2 expression and not JNK. We were able to show that another stress-activated kinase takes part in activation of the IRS2 promoter in HepG2 cells. After inhibition of cAMP dependant kinase (AMPK) IRS2 promoter activity fell down to $50 \%$ (Fig. 2E). AMPK is activated if cells run out of energy because ATP/ADP ratio is too low. But the loss of activity after AMPK inhibition was only minor compared to ERK inhibition.

Inhibition of p38MAPK with SB202190 increased basal IRS2 promoter activity in luciferase reporter assays. Interestingly, inhibition of p38MAPK after $\mathrm{H}_{2} \mathrm{O}_{2}$ stimulation increases promoter activity even further. Consequently, there is an inhibitory effect of p38MAPK on the IRS2 promoter. In this context it has been shown that there is a negative regulation of p38MAPK in ERK mediated transcription of the LDL receptor promoter. A possible mechanism might be that inhibition of p38MAPK increases ERK phosphorylation and activation (Singh et al. 1999, Au et al. 2003, Keeton et al. 2003).

SP1 has also been reported to provide a mechanism for glucose responsiveness. In adipocytes, glucose administration increased SP1 binding on the acetylCoA carboxylase gene promoter and increased transcription (Daniel \& Kim 1996). Glucose also induced IRS2 expression in rat primary pancreatic $\beta$-cells (Lingohr et al. 2006). Therefore, we tested glucose-induced transcription of the IRS2 promoter in our luciferase reporter system. As shown in Fig. 6A, we were not able to induce IRS2 promoter activity in HepG2 cells with increasing amounts of glucose. Thiazolidinediones, which promote insulin sensitivity in humans by PPAR $\gamma$ activation increased IRS2 gene expression in 3T3-L1 cells and human adipocytes (Smith et al. 2001). Moreover, pioglitazone induced IRS1 but not IRS2 expression in muscle (Hammarstedt \& Smith 2003). In our system the IRS2 luciferase reporter constructs did not show any differences in activity after rosiglitazone treatment, but we found a decrease of promoter activity after PPAR $\gamma$ overexpression in HepG2 cells that is proportional to the transfected DNA amount (Fig. 6B). Thus, thiazolidinediones do not seem to mediate their effects through PPAR $\gamma$ induced IRS2 promoter activation in liver cells.

We conclude, that 1) for basal activation of the IRS2 promoter in human HepG2 hepatoma cells, SP1 or NFI binding to a specific promoter region $(-688$ to $-611 \mathrm{bp}$ ) is essential, 2) promoter activity induced by this region is dependent on ERK activation, 3) SP1 binding to this region of the IRS2 promoter is mediated by ERK, 4) oxidative stress increases IRS2 expression via ERK activation, 5) IL1B mediated MAPK signaling increases IRS2 promoter activity similarly to oxidative stress, whereas IRS1 promoter activity decreased in response to IL1B in HepG2 hepatoma cells, and 6) these effects are cell type and IRS-gene promoter specific.

\section{Supplementary data}

This is linked to the online version of the paper at http://dx.doi.org/ 10.1677/JME-08-0182.

\section{Declaration of interest}

For M Udelhoven, U Leeser, S Freude, M M Hettich, and J Schnitker there is no conflict of interest that could be perceived as prejudicing the impartiality of the research reported. M Laudes has received lecture fees from Novartis and Sanofi Aventis, W Krone has received lecture fees from Takeda, MSD, Essex Pharma, and Sanofi Aventis, M Schubert has received lecture fees from Bayer Schering Pharma, Novartis and Sanofi Aventis.

\section{Funding}

The authors received grants from the Koeln Fortune program (S Freude, M Schubert), Deutsche Diabetes Gesellschaft (S Freude, M Schubert), and Fritz-Thyssen Foundation Az. 10.06.2.209 (M Schubert)

\section{Acknowledgements}

We thank Prof. Dr N J Brunskill and Dr R S Chana, University of Leicester (UK) for providing the PPAR $\gamma$ expression construct pCMXPPAR $\gamma$. HuH7 cells were a kind gift from S Schael and Dr M Plomann, Institute of Biochemistry, University of Cologne. GT1-7 cells were a kind gift from Dr J J Rochford, Institute of Metabolic Science, Metabolic Research Laboratories University of Cambridge (UK). We also thank Prof. Dr R C Bargou and Dr T Stuehmer, Department of Internal Medicine II, Division of Hematology and Medical Oncology, University Hospital Wuerzburg for providing pSuper ERK-1/-2 siRNA expression constructs in no time at all.

\section{References}

Au WS, Kung HF \& Lin MC 2003 Regulation of microsomal triglyceride transfer protein gene by insulin in HepG2 cells: roles of MAPKerk and MAPKp38. Diabetes 52 1073-1080. 
Biddinger SB \& Kahn CR 2006 From mice to men: insights into the insulin resistance syndromes. Annual Review of Physiology 68 123-158.

Boissan M, Beurel E, Wendum D, Rey C, Lecluse Y, Housset C, Lacombe ML \& Desbois-Mouthon C 2005 Overexpression of insulin receptor substrate-2 in human and murine hepatocellular carcinoma. American Journal of Pathology 167 869-877.

Burks DJ, Font de Mora J, Schubert M, Withers DJ, Myers MG, Towery HH, Altamuro SL, Flint CL \& White MF 2000 IRS-2 pathways integrate female reproduction and energy homeostasis. Nature 407 377-382.

Cantarini MC, de la Monte SM, Pang M, Tong M, D’Errico A, Trevisani F \& Wands JR 2006 Aspartyl-asparagyl beta hydroxylase over-expression in human hepatoma is linked to activation of insulin-like growth factor and notch signaling mechanisms. Hepatology 44 446-457.

Cross DA, Alessi DR, Cohen P, Andjelkovich M \& Hemmings BA 1995 Inhibition of glycogen synthase kinase- 3 by insulin mediated by protein kinase B. Nature 378 785-789.

Cui XJ, Kim HJ, Kuiatse I, Kim H, Brown PH \& Lee AV 2006 Epidermal growth factor induces insulin receptor substrate-2 in breast cancer cells via c-Jun $\mathrm{NH}_{2}$-terminal kinase/activator protein-1 signaling to regulate cell migration. Cancer Research 66 5304-5313.

Daniel S \& Kim KH 1996 Sp1 mediates glucose activation of the acetyl-CoA carboxylase promoter. Journal of Biological Chemistry 271 1385-1392.

Darne CH, Morel L, Claessens F, Manin M, Fabre S, Veyssiere G, Rombauts W \& Jean CL 1997 Ubiquitous transcription factors NF1 and $\mathrm{Sp} 1$ are involved in the androgen activation of the mouse vas deferens protein promoter. Molecular and Cellular Endocrinology 132 13-23.

Dearth RK, Cui X, Kim HJ, Kuiatse I, Lawrence NA, Zhang X, Divisova J, Britton OL, Mohsin S, Allred DC et al. 2006 Mammary tumorigenesis and metastasis caused by overexpression of insulin receptor substrate 1 (IRS-1) or IRS-2. Molecular and Cellular Biology 26 9302-9314.

Escribano O, Fernandez-Moreno MD, Zueco JA, Menor C, Fueyo J, Ropero RM, Diaz-Laviada I, Roman ID \& Guijarro LG 2003 Insulin receptor substrate-4 signaling in quiescent rat hepatocytes and in regenerating rat liver. Hepatology 37 1461-1469.

Fisher TL \& White MF 2004 Signaling pathways: the benefits of good communication. Current Biology 14 R1005-R1007.

Foti D, Iuliano R, Chiefari E \& Brunetti A 2003 A nucleoprotein complex containing Sp1, C/EBP beta, and HMGI-Y controls human insulin receptor gene transcription. Molecular and Cellular Biology 23 2720-2732.

Hall RK, Wang XL, George L, Koch SR \& Granner DK 2006 Insulin represses PEPCK gene transcription by causing the rapid disruption of an active transcription complex: a potential epigenetic effect. Molecular Endocrinology 21 550-563.

Hammarstedt A \& Smith U 2003 Thiazolidinediones (PPARgamma ligands) increase IRS-1, UCP-2 and C/EBPalpha expression, but not transdifferentiation, in L6 muscle cells. Diabetologia 46 48-52.

Hirankarn N, Kimkong I, Kummee P, Tangkijvanich P \& Poovorawan Y 2006 Interleukin-1beta gene polymorphism associated with hepatocellular carcinoma in hepatitis B virus infection. World Journal of Gastroenterology 12 776-779.

Hirashima Y, Tsuruzoe K, Kodama S, Igata M, Toyonaga T, Ueki K, Kahn CR \& Araki E 2003 Insulin down-regulates insulin receptor substrate-2 expression through the phosphatidylinositol 3-kinase/Akt pathway. Journal of Endocrinology 179 253-266.

Huynh H, Nguyen TT, Chow KH, Tan PH, Soo KC \& Tran E 2003 Overexpression of the mitogen-activated protein kinase (MAPK) kinase (MEK)-MAPK in hepatocellular carcinoma: its role in tumor progression and apoptosis. BMC Gastroenterology 319.

Huynh H, Soo KC, Chow PK \& Tran E 2007 Targeted inhibition of the extracellular signal-regulated kinase kinase pathway with AZD6244 (ARRY-142886) in the treatment of hepatocellular carcinoma. Molecular Cancer Therapeutics 6 138-146.
Ide T, Shimano H, Yahagi N, Matsuzaka T, Nakakuki M, Yamamoto T, Nakagawa Y, Takahashi A, Suzuki H, Sone H et al. 2004 SREBPs suppress IRS-2-mediated insulin signalling in the liver. Nature Cell Biology 6 351-357.

Jackson JG, Zhang X, Yoneda T \& Yee D 2001 Regulation of breast cancer cell motility by insulin receptor substrate-2 (IRS-2) in metastatic variants of human breast cancer cell lines. Oncogene 20 $7318-7325$.

Jones KA, Kadonaga JT, Rosenfeld PJ, Kelly TJ \& Tjian R 1987 A cellular DNA-binding protein that activates eukaryotic transcription and DNA replication. Cell 48 79-89.

Keeton AB, Bortoff KD, Bennett WL, Franklin JL, Venable DY \& Messina JL 2003 Insulin-regulated expression of Egr-1 and Krox20: dependence on ERK1/2 and interaction with p38 and PI3-kinase pathways. Endocrinology 144 5402-5410.

Laniel MA, Poirier GG \& Guerin SL 2001 Nuclear factor 1 interferes with $\mathrm{Sp} 1$ binding through a composite element on the rat poly(ADP-ribose) polymerase promoter to modulate its activity in vitro. Journal of Biological Chemistry 276 20766-20773.

Lee JY, Han CY, Yang JW, Smith C, Kim SK, Lee EY, Kim SG \& Kang KW 2007 Induction of glutathione transferase in insulin-like growth factor type I receptor-overexpressed hepatoma cells. Molecular Pharmacology 72 1082-1093.

Lingohr MK, Briaud I, Dickson LM, McCuaig JF, Alárcon C, Wicksteed BL \& Rhodes CJ 2006 Specific regulation of IRS-2 expression by glucose in rat primary pancreatic islet beta-cells. Journal of Biological Chemistry 281 15884-15892.

Maor S, Mayer D, Yarden RI, Lee AV, Sarfstein R, Werner H \& Papa MZ 2006 Estrogen receptor regulates insulin-like growth factor-I receptor gene expression in breast tumor cells: involvement of transcription factor Sp1. Journal of Endocrinology 191 605-612.

Merchant JL, Du M \& Todisco A 1999 Sp1 phosphorylation by Erk 2 stimulates DNA binding. Biochemical and Biophysical Research Communications 254 454-461.

Nagle JA, Ma Z, Byrne MA, White MF \& Shaw LM 2004 Involvement of insulin receptor substrate 2 in mammary tumor metastasis. Molecular and Cellular Biology 24 9726-9735.

Nakagawa Y, Shimano H, Yoshikawa T, Ide T, Tamura M, Furusawa M, Yamamoto T, Inoue N, Matsuzaka T, Takahashi A et al. 2006 TFE3 transcriptionally activates hepatic IRS-2, participates in insulin signaling and ameliorates diabetes. Nature Medicine 12 $107-113$.

Rafty LA, Santiago FS \& Khachigian LM 2002 NF1/X represses PDGF A-chain transcription by interacting with $\mathrm{Spl}$ and antagonizing Sp1 occupancy of the promoter. EMBO Journal 21 334-343.

Saltiel AR \& Kahn CR 2001 Insulin signalling and the regulation of glucose and lipid metabolism. Nature 414 799-806.

Schubert M, Brazil DP, Burks DJ, Kushner JA, Ye J, Flint CL, Farhang-Fallah J, Dikkes P, Warot XM, Rio C et al. 2003 Insulin receptor substrate-2 deficiency impairs brain growth and promotes tau phosphorylation. Journal of Neuroscience $\mathbf{2 3}$ 7084-7092.

Shang Y, Hu X, DiRenzo J, Lazar MA \& Brown M 2000 Cofactor dynamics and sufficiency in estrogen receptor-regulated transcription. Cell 103 843-852.

Shepherd PR, Withers DJ \& Siddle K 1998 Phosphoinositide 3-kinase: the key switch mechanism in insulin signalling. Biochemical Journal 333 471-490.

Shimano H 2007 SREBP-1c and TFE3, energy transcription factors that regulate hepatic insulin signaling. Journal of Molecular Medicine $\mathbf{8 5}$ 437-444.

Singh RP, Dhawan P, Golden C, Kapoor GS \& Mehta KD 1999 One-way cross-talk between p38(MAPK) and p42/44(MAPK). Inhibition of p38(MAPK) induces low density lipoprotein receptor expression through activation of the $\mathrm{p} 42 / 44$ (MAPK) cascade. Journal of Biological Chemistry 274 19593-19600. 
Smith U, Gogg S, Johansson A, Olausson T, Rotter V \& Svalstedt B 2001 Thiazolidinediones (PPARgamma agonists) but not PPARalpha agonists increase IRS-2 gene expression in 3T3-L1 and human adipocytes. FASEB Journal 15 215-220.

Sun XJ, Miralpeix M, Myers MG Jr, Glasheen EM, Backer JM, Kahn CR \& White MF 1992 Expression and function of IRS-1 in insulin signal transmission. Journal of Biological Chemistry 267 22662-22672.

Sun XJ, Wang LM, Zhang Y, Yenush L, Myers MG Jr, Glasheen E, Lane WS, Pierce JH \& White MF 1995 Role of IRS-2 in insulin and cytokine signalling. Nature 377 173-177.

Suske G 1999 The Sp-family of transcription factors. Gene 238 291-300.

Szabó P, Moitra J, Rencendorj A, Rákhely G, Rauch T \& Kiss I 1995

Identification of a nuclear factor-I family protein-binding site in the silencer region of the cartilage matrix protein gene. Journal of Biological Chemistry 270 10212-10221.

Tanaka Y, Furuta T, Suzuki S, Orito E, Yeo AE, Hirashima N, Sugauchi F, Ueda R \& Mizokami M 2003 Impact of interleukin-1beta genetic polymorphisms on the development of hepatitis $\mathrm{C}$ virus-related hepatocellular carcinoma in Japan. Journal of Infectious Diseases 187 $1822-1825$.

Tien KM \& Savaraj N 2006 Roles of reactive oxygen species in hepatocarcinogenesis and drug resistance gene expression in liver cancers. Molecular Carcinogenesis 45 701-709.
Valverde AM, Mur C, Pons S, Alvarez AM, White MF, Kahn CR \& Benito M 2001 Association of insulin receptor substrate 1 (IRS-1) y895 with Grb-2 mediates the insulin signaling involved in IRS-1-deficient brown adipocyte mitogenesis. Molecular and Cellular Biology 21 2269-2280.

Vassen L, Wegrzyn W \& Klein-Hitpass L 1999 Human insulin receptor substrate-2: gene organization and promoter characterization. Diabetes 48 1877-1880.

Yamada M, Ohnishi H, Sano S, Nakatani A, Ikeuchi T \& Hatanaka H 1997 Insulin receptor substrate (IRS)-1 and IRS-2 are tyrosinephosphorylated and associated with phosphatidylinositol 3-kinase in response to brain-derived neurotrophic factor in cultured cerebral cortical neurons. Journal of Biological Chemistry 272 30334-30339.

Zhang J, Ou J, Bashmakov Y, Horton JD, Brown MS \& Goldstein JL 2001 Insulin inhibits transcription of IRS-2 gene in rat liver through an insulin response element (IRE) that resembles IREs of other insulin-repressed genes. PNAS 98 3756-3761.

Received in final form 10 September 2009

Accepted 14 September 2009

Made available online as an Accepted Preprint

16 September 2009 